\title{
Promoting effects of an extended photoperiod treatment on the condition of hair coats and gonadal function in Thoroughbred weanlings
}

\author{
Takehiro HARADA ${ }^{1,2}$, Yasuo NAMBO ${ }^{1,3}$, Mutsuki ISHIMARU ${ }^{4}$, Fumio SATO ${ }^{1,4}$, \\ Kentaro NAGAOKA ${ }^{1,2}$, Gen WATANABE ${ }^{1,2}$ and Kazuyoshi TAYA ${ }^{2,5 *}$ \\ ${ }^{1}$ United Graduate School of Veterinary Sciences, Gifu University, Gifu 501-1 193, Japan \\ ${ }^{2}$ Laboratory of Veterinary Physiology, Cooperative Department of Veterinary Medicine, Faculty of Agriculture, Tokyo \\ University of Agriculture and Technology, Tokyo 183-8509, Japan \\ ${ }^{3}$ Department of Clinical Veterinary Science, Obihiro University of Agriculture and Veterinary Medicine, Hokkaido \\ 080-8555, Japan \\ ${ }^{4}$ Hidaka Training and Research Center, Japan Racing Association, Hokkaido 057-0171, Japan \\ ${ }^{5}$ Shadai Corporation, Hokkaido 059-1432, Japan
}

The effects of an extended photoperiod (EP) treatment (14.5 hr light, $9.5 \mathrm{hr}$ dark) on Thoroughbred colts and fillies from December 25 at 7-9 months old to the following May at 12-14 months old on coat condition and gonadal functions were investigated. Coat condition was evaluated in April. The colts and fillies in the EP treatment group changed from winter to summer coats (molting of winter coats), whereas those in the control group did not. To determine the day of first ovulation, the plasma concentrations of progesterone were measured once a month in fillies. The day of first ovulation was advanced in the EP treatment fillies compared with the control fillies. The present study clearly demonstrated that the EP treatment advanced the molting of winter coats and advanced ovulation in fillies, even in weanlings.

Key words: extended photoperiod treatment, gonadal function, molting of winter coat, progesterone, Thoroughbred weanling

\author{
J. Equine Sci. \\ Vol. 26, No. 4 \\ pp. 147-150, 2015
}

In seasonal breeders, there is evidence for the involvement of both photoperiodic cues and maturity in the onset of puberty $[2,5,12]$. The photoperiodic information is thought to be conveyed to the reproductive axis via changes in the circulating concentrations of melatonin and prolactin $[2,5]$. Extended photoperiod (EP) treatment activates the ovarian function earlier in broodmares, and it is widely used to advance the ovulation time in husbandry [15], because horses are typical long-day seasonal breeders. It has recently been reported that an EP treatment was applied to yearling horses and that it promoted growth rates, increased muscle mass, and advanced activation of gonadal function and

Received: October 19, 2015

Accepted: November 13, 2015

*Corresponding author. e-mail: taya@cc.tuat.ac.jp

(C)2015 Japanese Society of Equine Science

This is an open-access article distributed under the terms of the Creative Commons Attribution Non-Commercial No Derivatives (bync-nd) License $<$ http://creativecommons.org/licenses/by-nc-nd/3.0/>. coat molting $[10,13,17]$. The aim of the present study was to investigate whether EP treatment could successfully advance the annual molting pattern and gonadal function in Thoroughbred weanlings.

Animals: Twenty-nine Thoroughbreds (11 colts and 18 fillies) born in 2006 and reared in the Hidaka, Hokkaido, Japan, were used. Fifteen of them ( 8 colts and 7 fillies) were subjected to EP treatment from December 25, 2006, to May 7, 2007, and the remaining 14 horses ( 3 colts and 11 fillies) were reared under natural light alone as a control group. The test horses were 7-10 months old at the time of experiment initiation. All procedures were carried out in accordance with the guidelines for use of horses established by Hidaka Training and Research Center.

Extended photoperiod treatment: A 100-watt white bulb was set near the ceilings of stalls $(3.6 \times 3.6 \mathrm{~m})$, and the lighting conditions were $14.5 \mathrm{hr}$ of light and $9.5 \mathrm{hr}$ of dark. The intensity of illumination under the bulb at the height of the horse's head was approximate 100 lux. This lighting 
condition was selected because it was considered to mimic the daylight in May in Hokkaido, Japan.

Estimation of the condition of hair coats: The condition of the hair coat was evaluated in April in 10 arbitrary selected horses (5 control and 5 EP). Eight examiners randomly evaluated the hair of yearlings in April, using a 3-point scoring method: "excellent", "normal", and "poor" were scored 3, 2, and 1, respectively, and the mean scores were compared.

Collection of blood: Blood was collected from the jugular vein into heparinized vacutainers $(10 \mathrm{~m} l)$ once a month from December until the following May in fillies. Plasma was harvested and stored at $-20^{\circ} \mathrm{C}$ until assayed.

Determination of the first ovulation: The day seven days before the day on which the plasma concentration of progesterone initially reached $1 \mathrm{ng} / \mathrm{m} l$ or higher was arbitrarily designated as the day of first ovulation.

Hormone assays: Plasma concentrations of progesterone were determined by time-resolved fluoroimmunoassay using dissociation-enhanced lanthanide fluorescence immunoassay (DELFIA) systems (PerkinElmer, Waltham, MA, U.S.A.) as described previously [9, 14]. The intra- and inter-assay coefficients of variation were $5.5 \%$ and $8.6 \%$.

Statistical analysis: Mann-Whitney $U$-test was used in comparison of scores for hair coat condition between the EP treatment group and control group. $P<0.05$ was considered to be statistically significant.

Changes in molting of winter coats: Representative photographs taken in April at 11-13 months old (4 months after EP treatment initiation) in the two groups are shown in Fig. 1, and graphs of the scores of the two groups are shown in Fig. 2. As shown in the representative photographs for the colts and fillies (Fig. 1), the winter coats remained in colts (Fig. 1A) and a fillies (Fig. 1C) in the control group, whereas molting of winter coats was advanced in colts (Fig. 1B) and fillies (Fig. 1D) of the EP treatment group. Furthermore, the coat condition score was significantly higher in the EP treatment group than the control group (Fig. 2).

Endocrine changes in fillies: The plasma concentration of progesterone was markedly different between the two groups. It remained at the baseline level from December to March in the control group (Fig. 3A), but it rose to higher level than that in the control group in February and remained at a high level with marked periodic variation thereafter in the EP treatment group (Fig. 3B).

Day of the first ovulation: Assuming that the day seven days before the day on which the plasma concentration of progesterone first reached $1 \mathrm{ng} / \mathrm{m} l$ or higher was the day of first ovulation, no ovulation was noted before April in the control group $(0 \%)$, but it occurred in 5 out of 7 fillies (71.43\%) before April in the EP treatment group.

In the present study, the effects of EP treatment on the condition of the hair coat and gonads in Thoroughbred weanlings were investigated. The present study demonstrated for first time that EP treatment promotes the change from winter to summer coats (molting of winter coats) in weanlings. The EP treatment advanced early elevation of circulating progesterone in fillies, indicating that EP treatment also activates the gonadal function and ovulation in weanlings as well as broodmares and yearlings $(10,13,15,17)$.

Puberty is a process that results from a complex series of coordinated neuroendocrine changes leading to internal and external physical changes in primary and secondary sexual characteristics and eventual reproductive competence. The our previous paper clearly demonstrated that the hypothalamic-pituitary axis in the first breeding season is already responsive to changes in photoperiod and secretes prolactin in a manner similar to that in adult horses but that the pituitary is less sensitive in terms of gonadotropin secretion [5]. Considering puberty as a point when progesterone levels exceed $2 \mathrm{ng} / \mathrm{m} l$ and rise by 2 standard deviations (SDs) above the average value, the fillies reach puberty by 52 weeks of age in the southern hemisphere [2]. This is also true in Thoroughbred fillies born in Japan in the northern hemisphere [5]. Our previous papers also reported that molting of the winter hair coat and gonadal function were stimulated by long-day EP treatment in Thoroughbred yearlings reared in Japan $[10,13,17]$. In our previous studies, prolactin in both sexes correlated positively with the day length. In fact, an earlier study in stallions and geldings showed that the correlation is stronger with the day length than with temperature [4]. It is a known fact that melatonin secretion is lower during longer photoperiods. The prolactin secretion of the mare is negatively regulated by melatonin during the spring and early summer months [8]. Notably, the prolactin concentrations were similar between the first two breeding seasons after birth in both colts and fillies [5]. These results in conjunction with those of the present study strongly suggest that prolactin may have been involved in the promotion of molting observed in the weanlings. In a wide range of mammals adapted to cold and temperate climates, there is a close association between the seasonal cycle in the secretion of prolactin and the seasonal changes in the hair coat. High circulating concentrations of prolactin are associated with growth of the summer coat, and low circulating concentrations of prolactin are associated with development of the winter coat in the Djungarian hamster [7], blue fox [16], sheep [1, 11], goat [6], and deer [3]. In addition, the possibility that prolactin is causally involved in regulating the seasonal pelage cycle has been investigated experimentally in the Djungarian hamster [7], blue fox [16] and red deer [3].

In conclusion, the present study clarified that the molting of winter coats and gonadal function are activated by EP 


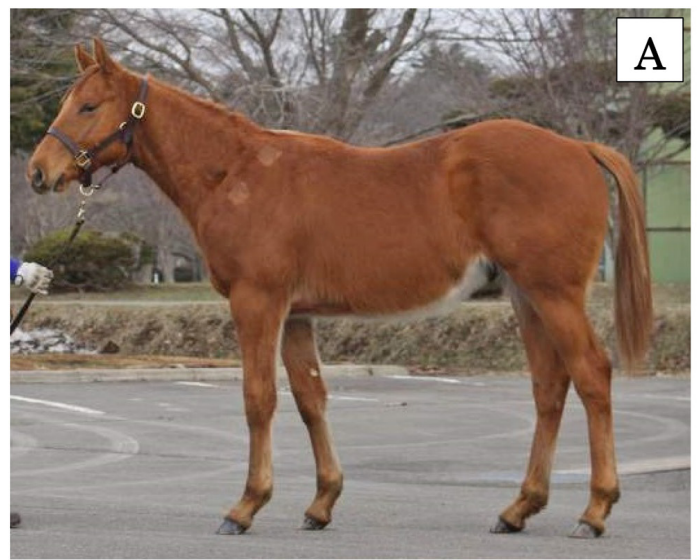

Control

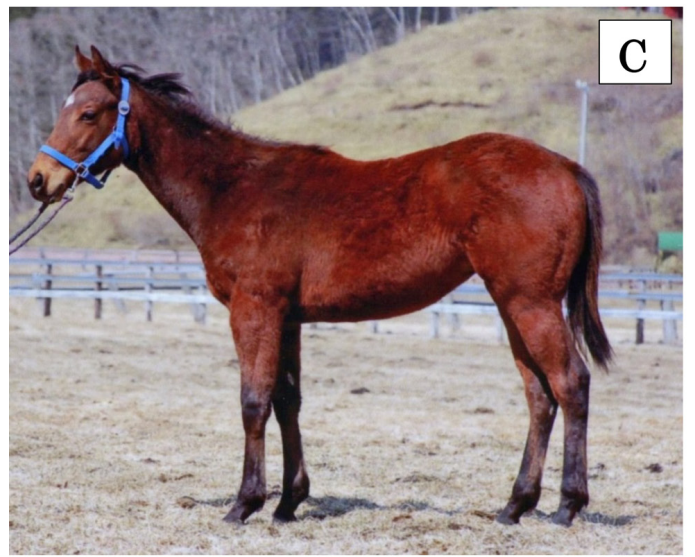

Control

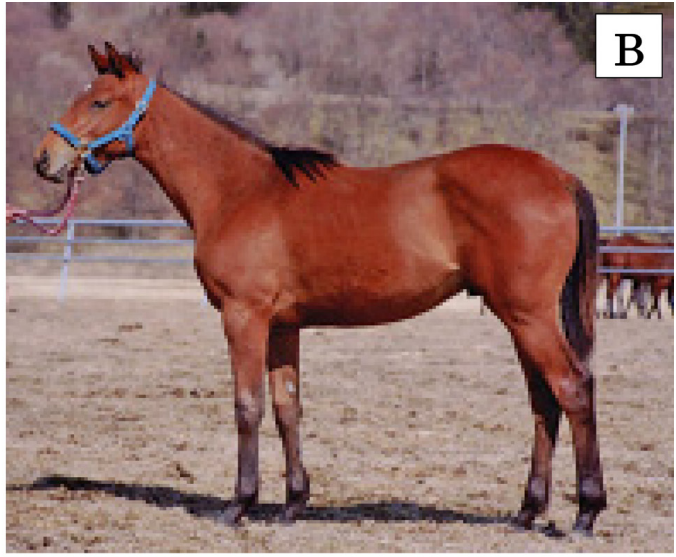

Extended photoperiod

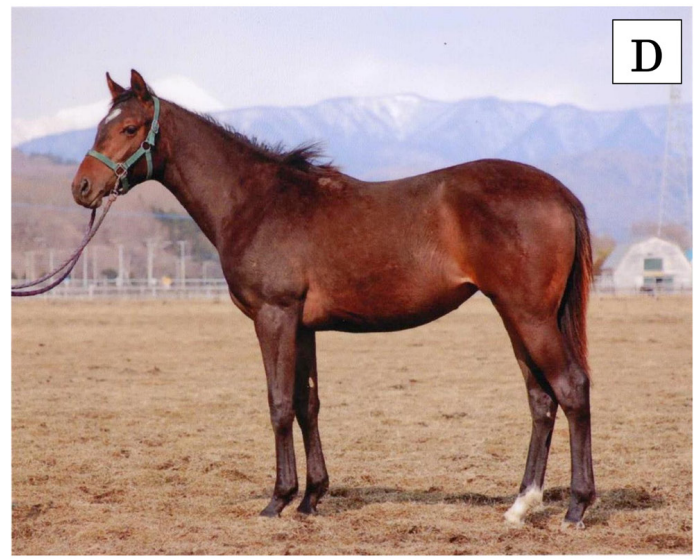

Extended photoperiod

Fig. 1. Comparison of the hair coat conditions of representative colts (A, B) and fillies (C, D) in the control group $(A, C)$ and extended photoperiod treatment group (B, D) in April at one year old.

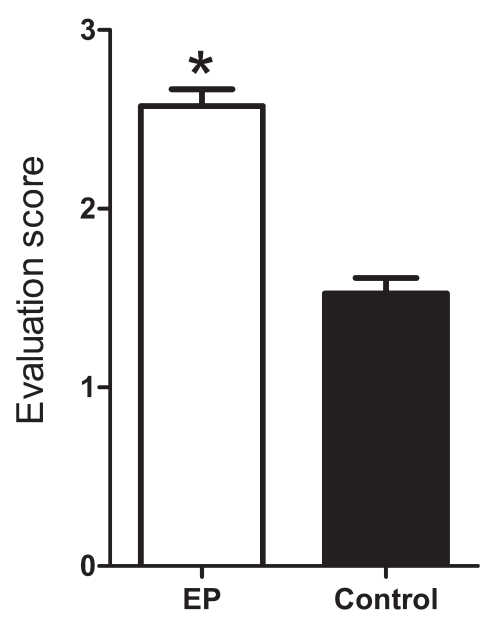

Fig. 2. Comparison of scores of hair coat condition between the extended photoperiod treatment group $(E P, \square)$ and control group (Control, $\mathbf{a})$ in April. Results are expressed as the mean \pm SEM. $* P<0.05$. treatment in weanlings similarly to those in broodmares and yearlings, suggesting that strengthening of muscles and increasing the bone mineral density by promoting secretion of steroid hormones from the gonads may reduce the risks of training during rearing from the weanling to yearling stage.

\section{References}

1. Allain, D., Ravault, J.P., Panaretto, B.A., and Rougeot, J. 1986. Effects of pinealectomy on photoperiodic control of hair follicle activity in the Limousine ram: possible relationships with plasma prolactin levels. J. Pineal Res. 3: 25-32. [Medline] [CrossRef]

2. Brown-Douglas, C.G., Firth, E.C., Parkinson, T.J., and Fennessy, P.F. 2004. Onset of puberty in pasture-raised Thoroughbreds born in southern hemisphere spring and autumn. Equine Vet. J. 36: 499-504. [Medline] [CrossRef]

3. Curlewis, J.D., Loudon, A.S.I., Milne, J.A., and McNeilly, A.S. 1988. Effects of chronic long-acting bromocrip- 

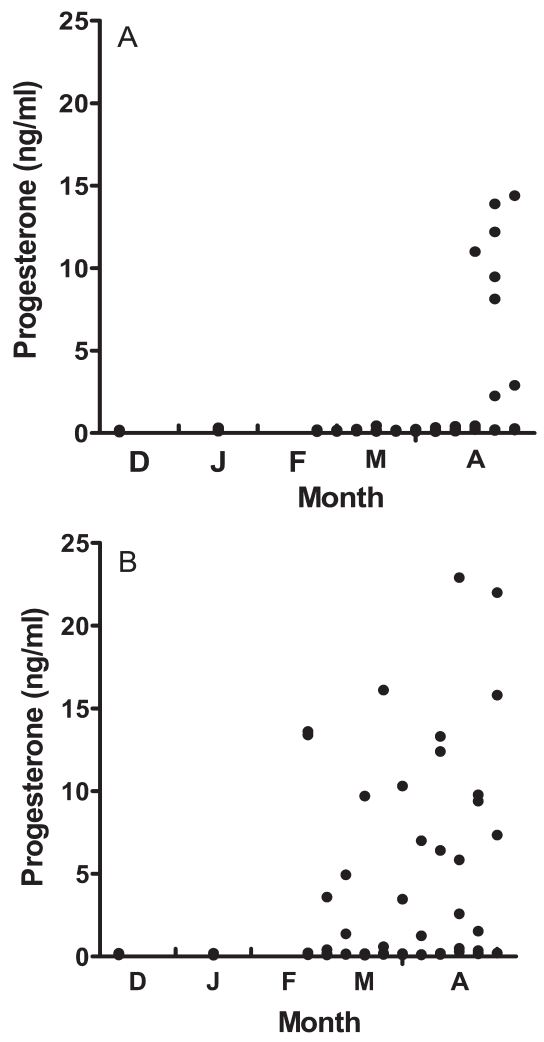

Fig. 3. Changes in plasma concentrations of progesterone (A, B) in individual Thoroughbred fillies in the control (A) and extended photoperiod treatment groups (B) from December at the weanling stage to May at the yearling stage. Letters represent the first letter of each month.

tine treatment on liveweight, voluntary food intake, coat growth and breeding season in non-pregnant red deer hinds. J. Endocrinol. 119: 413-420. [Medline] [CrossRef]

4. Dhakal, P., Tsunoda, N., Nakai, R., Kitaura, T., Harada, T., Ito, M., Nagaoka, K., Toishi, Y., Taniyama, H., Watanabe, G., and Taya, K. 2011. Annual changes in day-length, temperature, and circulating reproductive hormones in Thoroughbred stallions and geldings. J. Equine Sci. 22: 29-36. [Medline] [CrossRef]

5. Dhakal, P., Hirama, A., Nambo, Y., Harada, T., Sato, F., Nagaoka, K., Watanabe, G., and Taya, K. 2012. Circulating pituitary and gonadal hormones in spring-born Thoroughbred fillies and colts from birth to puberty. J. Reprod. Dev. 58: 522-530. [Medline] [CrossRef]

6. Dicks, P., Russel, A.J., and Lincoln, G.A. 1994. The role of prolactin in the reactivation of hair follicles in relation to moulting in cashmere goats. J. Endocrinol. 143: 441-448. [Medline] [CrossRef]

7. Duncan, M.J., and Goldman, B.D. 1984. Hormonal regulation of the annual pelage color cycle in the Djungarian hamster, Phodopus sungorus. II. Role of prolactin. J. Exp. Zool. 230: 97-103. [Medline] [CrossRef]

8. Fitzgerald, B.P., Davison, L.A., and McManus, C.J. 2000. Evidence for a seasonal variation in the ability of exogenous melatonin to suppress prolactin secretion in the mare. Domest. Anim. Endocrinol. 18: 395-408. [Medline] [CrossRef]

9. Korosue, K., Murase, H., Sato, F., Ishimaru, M., Watanabe, G., Harada, T., Taya, K., and Nambo, S. 2013. Changes in serum concentrations of prolactin, progestogens, and estradiol$17 \beta$ and biochemical parameters during peripartum in an agalactic mare. J. Equine Vet. Sci. 33: 279-286. [CrossRef]

10. Kunii, H., Nambo, Y., Okano, A., Matsui, A., Ishimaru, M., Asai, Y., Sato, F., Fujii, K., Nagaoka, K., Watanabe, G., and Taya, K. 2015. Effects of an extended photoperiod on gonadal function and condition of hair coats in Thoroughbred colts and fillies. J. Equine Sci. 26: 57-66. [Medline] [CrossRef]

11. Lincoln, G.A. 1990. Correlation with changes in horns and pelage, but not reproduction, of seasonal cycles in the secretion of prolactin in rams of wild, feral and domesticated breeds of sheep. J. Reprod. Fertil. 90: 285-296. [Medline] [CrossRef]

12. Mizukami, H., Suzuki, T., Nambo, Y., Ishimaru, M., Naito, H., Korosue, K., Akiyama, K., Miyata, K., Yamanobe, A., Nagaoka, K., Watanabe, G., and Taya, K. 2015. Comparison of growth and endocrine changes in Thoroughbred colts and fillies reared under different climate conditions. J. Equine Sci. 26: 49-56. [Medline] [CrossRef]

13. Nambo, Y., Okano, A., Kunii, H., Harada, T., Dhakal, P., Matsui, A., Korosue, K., Yamanobe, A., Nagata, S., Watanabe, G., and Taya, K. 2010. Effect of extended photoperiod on reproductive endocrinology and body composition in thoroughbred yearlings and weanlings. Anim. Reprod. Sci. 121(Suppl.): S35-S37. [CrossRef]

14. Nambo, Y., Tatee, H., Kotoyori, Y., Komano, M., and Tanaka, H. 2009. Weekly changes in serum progesterone concentrations in pregnant thoroughbred mares, in comparison with seven mares with early pregnancy loss. $J$. Jpn. Vet. Med. Assoc. 62: 630-635.

15. Nishikawa, Y. 1959. Studies on Reproduction in Horses: Singularity and Artificial Control in Reproductive Phenomena. Japanese Racing Association, Tokyo.

16. Smith, A.J., Mondain-Monval, M., Simon, P., Andersen Berg, K., Clausen, O.P.F., Hofmo, P.O., and Scholler, R. 1987. Preliminary studies of the effects of bromocriptine on testicular regression and the spring moult in a seasonal breeder, the male blue fox (Alopex lagopus). J. Reprod. Fertil. 81: 517-524. [Medline] [CrossRef]

17. Suzuki, T., Mizukami, H., Nambo, Y., Ishimaru, M., Miyata, K., Akiyama, K., Koresue, K., Naito, H., Nagaoka, K., Watanabe, G., and Taya, K. 2015. Different effects of light treatment on growth, gonadal function and condition of hair coats in Thoroughbreds yearlings reared under different climate condition. J. Equine Sci. 26: 113-124. 